\title{
Comparison of outcomes of triamcinolone versus normal saline soaked polyvinyl alcohol pack following bilateral endoscopic sinus surgery*
}

\author{
Bigyan Raj Gyawali, Bibhu Pradhan, Narmaya Thapa
}

Department of ENT-HNS, Institute of Medicine, Tribhuvan University, Kathmandu, Nepal
Rhinology 57: 4, 287 - 292, 2019

https://doi.org/10.4193/Rhin 19.004

*Received for publication:

January 5, 2019

Accepted: March 25, 2018

\begin{abstract}
Background: Steroids have been proven to be beneficial in improving post-operative outcomes following sinus surgery. The ideal mode of delivery is to increase local concentration in the sinuses with minimal systemic side effects. In this study, we used triamcinolone soaked polyvinyl alcohol packs immediately following sinus surgery, and assessed the effects on post-operative outcomes.

Methodology: This was a prospective, interventional, and comparative study. Following endoscopic sinus surgery, a polyvinyl alcohol pack was placed in both nasal cavities and $4 \mathrm{ml}$ triamcinolone was infiltrated in one side and $4 \mathrm{ml}$ of normal saline was infiltrated in the other. The pack was removed on the second post-operative day and nasal cavities and paranasal sinuses were evaluated using a flexible endoscope in the third post-operative week using Lund-Kennedy and Peri-operative sinus endoscopic scores.
\end{abstract}

Results: There was a reduction in the average Lund-Kennedy score and Peri-operative sinus endoscopy score in the treatment site compared to the control site which was statistically significant. There was a greater reduction in crusting, oedema and scarring in the treatment site compared to the control site. However, only the reduction in oedema was statistically significant.

Conclusions: Triamcinolone soaked polyvinyl alcohol pack following endoscopic sinus surgery improves post-operative outcomes.

Key words: endoscopic sinus surgery, triamcinolone, Lund-Kennedy score, peri-operative sinus endoscopic (POSE) score, polyvinyl alcohol pack

\section{Introduction}

Wound healing is a significant determinant of successful outcome following endoscopic sinus surgery (ESS). Common causes of suboptimal results following endoscopic sinus surgery include recurrent inflammation and polyposis, adhesion/ synechiae formation, middle turbinate lateralization, and stenosis of the surgically enlarged sinus ostia. Various studies have shown beneficial effects of post-operative steroids in improving outcomes following ESS. However, the use of systemic steroids is associated with systemic complications. Also there is no strong evidence that topical steroids in a spray delivery system are beneficial due to insufficient concentration at the surgical site ${ }^{(1)}$. A systematic review done by Reychler et al. ${ }^{(2)}$ analyzed the efficacy of steroids delivered via nebulization in patients with chronic rhinosinusitis, which found that this was not superior to delivery by nasal sprays. 
Based on this evidence, this study aims to evaluate the effect of steroids, delivered locally, immediately following ESS, in improving early post-operative wound healing and endoscopic findings.

\section{General objectives}

To compare the post-operative outcomes of triamcinolone soaked polyvinyl alcohol pack versus normal saline soaked polyvinyl alcohol pack following bilateral endoscopic sinus surgery.

\section{Specific objectives}

- To assess the effect of triamcinolone soaked polyvinyl alcohol pack on post-operative oedema, crusting, secretion, scarring/ synechiae, middle turbinate lateralization and polypoidal mucosal change following bilateral endoscopic sinus surgery.

- To assess the effect of normal saline soaked polyvinyl alcohol pack on post-operative oedema, crusting, secretion, scarring/ synechiae, middle turbinate lateralization and polypoidal mucosal change following bilateral endoscopic sinus surgery.

- To compare the outcomes between two groups.

\section{Material and Methods}

Our study is a prospective, interventional and comparative study which was conducted in Ganesh Man Singh Memorial Academy for ENT- Head and Neck Studies, Maharajgunj Medical Campus, Tribhuvan University Teaching Hospital, Institute of Medicine, Kathmandu, Nepal. The study took place over 15 months from June 2015 to August 2016.

\section{Inclusion criteria}

- Age: $>15$ years

- All genders

- Patients requiring bilateral ESS (CRS with or without nasal polyposis)

\section{Exclusion criteria}

- Any history of intolerance to triamcinolone

- Patients requiring unilateral ESS

- History of previous sinus surgery

All cases which met inclusion criteria during the study were included. The total number of enrolled patients was 65 , of which seven patients could not be followed up on in the third postoperative week (POW). Thus, our final sample size was 58. Ethical committee approval was obtained from the institutional review board (IRB) of Maharajgunj Medical Campus, TUTH, Institute of Medicine, Kathmandu, Nepal. Consent from patients was also taken.

Symptomatic patients with CRS with or without polyposis were selected from OPD. Bilateral ESS was conducted by the relevant faculties. Cases with septal deviation obscuring the field of surgery underwent endoscopic septoplasty to improve access to the sinuses. Following surgery, polyvinyl alcohol packs measuring $4.5 \times 1.5 \times 2 \mathrm{~cm}$ were applied in the bilateral nasal cavities between the middle turbinate and septum and infiltrated with 4 $\mathrm{ml}$ triamcinolone $(40 \mathrm{mg} / \mathrm{ml})$ and $4 \mathrm{ml}$ normal saline as allocated by a lottery method. (Two folded pieces of paper with right and left side written on them, one of which was chosen blindly.) Following completion of surgery, the chosen side was infiltrated with Triamcinolone while the other side was infiltrated with normal saline. Nasal packs were removed on the second post-operative day. Patients were discharged on the third post-operative day with a prescription for systemic antibiotic Tab. Co-amoxyclav $(625 \mathrm{mg})$ to be taken eight hourly for two weeks. Oral steroids and antifungals were also prescribed according to need and diagnosis. Steroid sprays were to be used only after the third POW. Regarding douching, patients were advised to use one liter of cooled boiled water with one teaspoonful each of table salt and sodium bicarbonate used for cooking. Patients were examined in the third POW using a fibreoptic flexible endoscope in OPD by a single person to avoid observer bias. Findings were noted as per Lund Kennedy (LK) ${ }^{(3)}$ and peri-operative sinus endoscopy (POSE) score $^{(4)}$. Correction of septal deviation was also assessed. The examining faculty was blinded regarding which site received triamcinolone. Frontal and sphenoid sinuses were not assessed.

\section{Statistical analysis}

Comparisons of outcomes between the two groups were performed by paired t-test, Chi-square test and Fisher exact test. SPSS version 16 was used to analyze results. We regarded a $p$ value less than 0.05 as statistically significant.

\section{Results}

In this study 58 patients underwent bilateral endoscopic sinus surgery. In seven cases correction of the septal deviation was carried out to improve access to the sinus. Although our inclusion criteria included cases of CRS with or without polyposis, all of the patients enrolled in our study had bilateral sinonasal polyposis. The observations recorded in this study are described under the following headings.

\section{Sex distribution}

Out of 58 patients 37 were male and 21 were female (Table 1).

\section{Age distribution}

Patients ranged from 15 to 66 years of age. The majority of patients fell in the 30-45 years age group (Table 1).

\section{Lund- Kennedy (LK) and Peri-operative Sinus Endoscopy (POSE)}

LK score and POSE score were assessed in the third POW (Table 2). There was statistically significant reduction in LK score and 
Table 1. Age and sex distribution.

\begin{tabular}{|lcc|}
\hline \multicolumn{1}{|c|}{ Age group } & Sex \\
& Male & Female \\
\hline 15-30 years & 15 & 6 \\
\hline $31-45$ years & 14 & 9 \\
\hline $46-60$ years & 7 & 6 \\
\hline 60 years & 1 & 0 \\
\hline
\end{tabular}

Table 2. Lund-Kennedy and peri-operative sinus endoscopy score (POSE) on third post-operative week.

\begin{tabular}{lccc} 
& $\begin{array}{c}\text { Treatment, } \\
\text { Range } \\
\text { (Average } \pm \text { SD) }\end{array}$ & $\begin{array}{c}\text { Control, } \\
\text { Range } \\
\text { (Average } \pm \text { SD) }\end{array}$ & t-test \\
\hline $\begin{array}{l}\text { Lund-Kennedy } \\
\text { score }\end{array}$ & $0-4$ & $0-5$ & $\mathrm{p}=0.0001$ \\
POSE score & $(0.53 \pm 0.922)$ & $(1.31 \pm 1.158)$ & \\
\hline
\end{tabular}

POSE score in the treatment group compared to the control group.

\section{Variations of Lund- Kennedy (LK) score}

There was overall reduction in crusting, oedema and scarring/ synechiae in the treatment site compared to the control site (Table 3). Reduction in oedema was statistically significant.

\section{Peri-operative Sinus Endoscopy (POSE) score variation on} third post-operative week

Endoscopic examination of nasal cavities and paranasal sinuses in the third POW based on POSE score showed overall reduction in synechiae of the middle turbinate, crusting, oedema, secretion and polypoidal mucosal change in the treatment site compared to the control site. However, incidence of lateralization of the middle turbinate was greater in the treatment site compared to the control site (Table 4).

\section{Discussion}

Wound healing is the significant factor to determine successful outcome following ESS. Factors leading to poor surgical outcomes include recurrent inflammation and polyposis, adhesion/ synechiae formation, middle turbinate lateralization, and stenosis of the surgically enlarged sinus ostia. Various studies have shown beneficial effect of steroids in improving postoperative outcomes. However, systemic steroids are associated with adverse side effects. Thus, the rationale of our study was to see whether topical application of steroids via nasal pack would improve post operative outcomes and minimize the systemic adverse effects.

All surgeries were performed by faculty groups and not having
Table 3. Lund- Kennedy score on third post-operative week

\begin{tabular}{|c|c|c|c|}
\hline & $\begin{array}{l}\text { Treatment } \\
\qquad(n=58)\end{array}$ & $\begin{array}{l}\text { Control } \\
(n=58)\end{array}$ & \\
\hline $\begin{array}{l}\text { Crusting } \\
\text { None } \\
\text { Mild } \\
\text { Severe }\end{array}$ & $\begin{array}{c}51 \\
6 \\
1\end{array}$ & $\begin{array}{c}36 \\
15 \\
7\end{array}$ & $\begin{array}{l}\text { Fisher exact test } \\
p \text { value }=0.092\end{array}$ \\
\hline $\begin{array}{l}\text { Oedema } \\
\text { None } \\
\text { Mild } \\
\text { Severe }\end{array}$ & $\begin{array}{c}46 \\
7 \\
5\end{array}$ & $\begin{array}{c}36 \\
13 \\
9\end{array}$ & $\begin{array}{l}\text { Chi-square test } \\
p \text { value }=0.005\end{array}$ \\
\hline $\begin{array}{l}\text { Scarring/ } \\
\text { Synechiae } \\
\text { None } \\
\text { Mild } \\
\text { Severe }\end{array}$ & $\begin{array}{c}52 \\
5 \\
1\end{array}$ & $\begin{array}{c}45 \\
12 \\
1\end{array}$ & $\begin{array}{l}\text { Fisher exact test } \\
p \text { value }=0.069\end{array}$ \\
\hline
\end{tabular}

Table 4. Peri-operative sinus endoscopy score (POSE) on third postoperative week.

\begin{tabular}{|c|c|c|c|}
\hline & $\begin{array}{l}\text { Treatment } \\
(n=58)\end{array}$ & $\begin{array}{l}\text { Control } \\
(n=58)\end{array}$ & \\
\hline $\begin{array}{l}\text { Middle } \\
\text { turbinate } \\
\text { Normal } \\
\text { Abnormal } \\
\text { a. Synechiae } \\
\text { b. Lateralization }\end{array}$ & $\begin{array}{l}52 \\
6 \\
1 \\
5\end{array}$ & $\begin{array}{c}46 \\
12 \\
10 \\
2\end{array}$ & $\begin{array}{l}\text { Fisher exact } \\
\text { test } \\
p \text { value }=1\end{array}$ \\
\hline $\begin{array}{l}\text { Middle meatus/MMA } \\
\text { Healthy } \\
\text { Narrowing/ closure }\end{array}$ & $\begin{array}{c}38 \\
0\end{array}$ & $\begin{array}{c}30 \\
0\end{array}$ & $\begin{array}{l}\text { Chi-square } \\
\text { test } \\
p \text { value }= \\
0.195\end{array}$ \\
\hline $\begin{array}{l}\text { Maxillary sinus contents } \\
\text { Mucoid secretion/ } \\
\text { oedema } \\
\text { Purulence/ allergic mucin }\end{array}$ & $\begin{array}{l}13 \\
7\end{array}$ & $\begin{array}{l}15 \\
13\end{array}$ & \\
\hline \multicolumn{4}{|l|}{ Anterior ethmoids } \\
\hline $\begin{array}{l}\text { Normal/ well healed } \\
\text { Abnormal }\end{array}$ & $\begin{array}{l}43 \\
15\end{array}$ & $\begin{array}{l}35 \\
23\end{array}$ & $\begin{array}{l}\text { Chi- square } \\
\text { test } \\
p \text { value }= \\
0.002\end{array}$ \\
\hline $\begin{array}{l}\text { Crusting } \\
\text { a. Mild } \\
\text { b. Extensive }\end{array}$ & $\begin{array}{l}5 \\
5 \\
0\end{array}$ & $\begin{array}{c}13 \\
9 \\
4\end{array}$ & $\begin{array}{l}\text { Fisher exact } \\
\text { test } \\
p \text { value }= \\
0.311\end{array}$ \\
\hline $\begin{array}{l}\text { Oedema } \\
\text { a. Mild } \\
\text { b. Diffuse }\end{array}$ & $\begin{array}{c}10 \\
6 \\
4\end{array}$ & $\begin{array}{l}13 \\
7 \\
6\end{array}$ & $\begin{array}{l}\text { Chi- square } \\
\text { test } \\
p \text { value }= \\
0.027\end{array}$ \\
\hline $\begin{array}{l}\text { Secretion } \\
\text { a. Mucoid } \\
\text { b. Purulence/ allergic } \\
\text { mucin }\end{array}$ & $\begin{array}{l}6 \\
4 \\
2\end{array}$ & $\begin{array}{l}8 \\
4 \\
4\end{array}$ & $\begin{array}{l}\text { Chi- square } \\
\text { test } \\
p \text { value }= \\
0.143\end{array}$ \\
\hline $\begin{array}{l}\text { Polypoid change } \\
\text { a. Mild } \\
\text { b. Diffuse }\end{array}$ & $\begin{array}{l}3 \\
1 \\
2\end{array}$ & $\begin{array}{l}6 \\
3 \\
3\end{array}$ & \\
\hline
\end{tabular}

a single surgeon was one of the major drawbacks of our study. Seven cases had to undergo septoplasty to improve access to the sinuses. This correction of gross septal deviation reduced 
the adverse outcomes such as synechiae on the site of deviation which would otherwise have confounded the results. Although the grading of endoscopic findings was entirely subjective, endoscopic assessment by a single person alleviated the chance of observation bias. Also, the examiner was blinded regarding which side received triamcinolone.

\section{Demographic statistics \\ Age distribution}

In our study the most commonly affected age group was 31-45 years accounting for $39.7 \%$, followed by $36.2 \%$ aged $15-30$ years, $22.4 \%$ aged $46-60$ years and $1.7 \%$ aged over 60 years. However, according to epidemiological analysis of patients with nasal polyposis by Bettega et al. ${ }^{(5)}$ polyposis is more common in the over 50 age group (37.5\%) and rarely affects children and young people. The findings of Bettega et al. were in accordance with those of Settipane et al. ${ }^{(6)}$, which showed that sinonasal polyposis increases with age and reaches its peak in those aged 50 years and older.

\section{Gender distribution}

In our study the male population was affected more (63.7\%) compared to the female population (36.3\%). One reason for this finding could be the increased prevalence of smoking in the male population. However, the epidemiological study by Bettega et al. concluded that the male population had lower prevalence of disease compared to females, accounting for $41.66 \%{ }^{(5)}$. In Settipane's review of 211 sinonasal polyposis patients, there was an equal distribution between the male (50.2\%) and female (49.8\%) population ${ }^{(6)}$. Similarly, a study by Jahromi et al. of 297 patients also showed higher prevalence of sinonasal polyposis in the male population $(60.3 \%)^{(7)}$.

Lund Kennedy and Peri-operative Sinus Endoscopy (POSE) score on third post-operative week

In our study, endoscopic assessment in the third POW showed LK score ranging from 0-4 with an average of 0.53 in the treatment site, which was lower in comparison to the control site with a range of 0-5 and an average of 1.31 . It was statistically a highly significant finding ( $p$ value $=0.0001$ ). Similarly, POSE score ranged from 0-8 in the treatment site with an average of 1.21 , and $0-8$ with an average of 1.95 in the control site. This difference was also statistically significant ( $p$ value $=0.004$ ).

Our findings were similar to those in the study by Côté et al. ${ }^{(1)}$, where Lund Kennedy score ranged from 1-5 with an average of 2.65 in the treatment site receiving triamcinolone impregnated nasal dressing, and 1-7 with an average of 3.59 in the control site in the second POW, which was significantly higher. Similarly, POSE score ranged from 1-8 in the treatment site with an average of 4.6, and 3-11 with an average of 6.84 in the control site. However, in the study by Rudmik et al. ${ }^{(8)}$ where dexamethasone eluting spacer was used, endoscopic evaluation in the fourth POW showed no significant difference on LK score between treatment and control group with an equivalent range of 2-10.

\section{Variations of Lund - Kennedy (LK) score Crusting}

In our study, overall reduction in crusting was noted in the treatment site compared to the control site. There was no crusting in $88 \%$ (51), mild crusting in $10.3 \%$ (6) and severe crusting in $1.7 \%$ (1) of patients in the treatment site, whereas in the control site there was no crusting in $62.06 \%$ (36), mild crusting in $25.8 \%$ (15) and severe crusting in $12.06 \%$ (7) of patients. This difference was not statistically significant with a $p$ value of 0.092 .

There is little in the literature regarding incidence of crusting in relation to use of post-operative topical steroids.

\section{Oedema}

In our study, we found a statistically significant reduction in oedema in the treatment site compared to the control site. There was no oedema in $79.3 \%$ (46), mild oedema in $12.06 \%$ (7) and severe oedema in $8.6 \%$ (5) of patients in the treatment site, whereas in the control site there was no oedema in $62.06 \%$ (36), mild oedema in $22.4 \%$ (13) and severe oedema in $15.5 \%$

(9) of patients. This difference was statistically significant with a $p$ value of 0.005 . Our finding was in accordance with the study by Murr et al. ${ }^{(9)}$, where visual analog rating of inflammation was statistically and clinically lower in sinuses with a steroid eluting stent from 3 to 6 weeks ( $p \leq 0.0032$ ) after surgery.

\section{Scarring/synechiae}

Synechiae formation is the most frequently occurring complication after FESS, ranging from 6 to $27 \%{ }^{(7)}$. In our study, though incidence of synechiae was higher in the control site compared to the treatment site, this finding couldn't yield statistical significance ( $p$ value $=0.069$ ). A study by Côté et al. ${ }^{(1)}$ showed a trend towards less synechiae formation in the nasal cavities receiving triamcinolone impregnated nasal dressing, but the data lacked statistical significance $(p<0.25)$. However, Han et al. ${ }^{(10)}$ in their study of 143 patients, showed a statistically significant $(p=$ 0.0013 ) reduction in incidence of adhesions in patients receiving post-operative steroid releasing sinus implants (4.2\%) compared to placebo (14.1\%). Murr et al. ${ }^{(9)}$ also found similar results in their study of 43 patients, where significant synechiae occurred in 5.3 $\%$ cases in the treatment group receiving post-operative steroid eluting stents compared to $21.1 \%$ of patients in the control group. This finding was statistically significant ( $p$ value $=0.0313$ ).

Peri-operative Sinus Endoscopy (POSE) score variation on third post-operative week

Middle turbinate

In our study, middle turbinate was normal in $89.7 \%$ (52) and 
abnormal in $10.3 \%$ (6) of patients in the treatment site, of which 1 patient had synechiae and 5 patients had lateralization. In the control site middle turbinate was normal in $79.4 \%$ (46) and abnormal in $20.6 \%$ (12) of patients, of which 10 patients had synechiae and 2 patients had lateralization. This difference was statistically insignificant with a $p$ value of 1 . Lateralization was found to be higher in the treatment rather than in the control site.

Lateralization is not affected by steroids, however it can be prevented by placement of a pack or stent lateral to the middle turbinate following surgery. Higher incidence of lateralization in our study might be due to not placing the pack lateral to the middle turbinate, rather than effect of drug.

In contrast to our study, Han et al. ${ }^{(10)}$ found middle turbinate lateralization occurred in $8.4 \%$ of the control group compared to $2.1 \%$ of the treatment group receiving steroid releasing sinus implants, which was statistically significant ( $p$ value $=0.0225$ ). Murr et al. ${ }^{(9)}$ found similar results. Middle turbinate lateralization occurred in 2 of 38 sinuses in the treatment group (5.3\%) compared to 6 of 38 sinuses in the control group (15.8\%) ( $p=$ 0.2188 ). Forwith et al. ${ }^{(11)}$ also had similar results with lateralization of the middle turbinate occurring in only 4 of 90 sinuses (4.4\%) receiving bio-absorbable steroid releasing sinus implant. Matheny et al. ${ }^{(12)}$, in their prospective study of 20 patients receiving steroid eluting implant following ESS on second and fourth post-operative week found complete middle turbinate lateralization in only $5 \%$ of sinuses.

\section{Middle meatus and maxillary antrum}

In our study, healing of the maxillary antrum was better in the treatment site, however it lacked statistical significance ( $p$ $=0.195$ ). In the treatment site the maxillary antrum was well healed in $65.6 \%$ (38) of patients and in $34.4 \%$ (20) of patients there were abnormal findings, of which 13 patients had mucoid secretion or oedema and 7 patients had purulent secretion. In the control site the maxillary antrum was well healed in $51.7 \%$ (30) and abnormal in $48.2 \%$ (28) of patients, of which 15 patients had mucoid secretion or oedema and 13 patients had purulent secretion. There was no middle meatal antrostomy narrowing or closure in both treatment and control sites.

\section{Anterior ethmoids}

Statistically significant improved healing of anterior ethmoids ( $p$ value $=0.002)$ and reduction of oedema $(p=0.027)$ and polypoidal mucosal change $(p=0.026)$ was seen in the treatment site compared to the control site.

Anterior ethmoids were well healed in $74.2 \%$ (43) of patients and abnormal with presence of crusting, oedema, secretion or polypoidal mucosal change in $25.8 \%$ (15) of patients in the treatment site, whereas in the control site anterior ethmoids were well healed in $60.3 \%$ (35) and abnormal in $39.7 \%$ (23) of patients. This difference was statistically significant with a $p$ value of 0.002 .

Our findings were similar to those of Murr et al. ${ }^{(9)}$, where in a study of 43 patients, there was reduction in inflammation of ethmoids with statistical and clinical significance at days 21, 30, and 45

( $p=0.0032,0.0011$, and 0.0022 , respectively) in patients receiving steroid eluting sinus stent compared to the control group. The incidence of polyposis was also lower in the treatment group (18.4\%) compared to the control group (36.8\%) which was statistically significant $(p=0.0391)$.

A study by Vento et al. ${ }^{(13)}$, which included 60 patients undergoing ESS receiving triamcinolone aerosol spray post-operatively, concluded that triamcinolone acetonide prevents the regrowth of nasal polyposis after polyp surgery in ASA-tolerant patients. Similarly, a study by Han et al. ${ }^{(10)}$ showed the rate of frank polyposis by day 30 following ESS was $36.9 \%$ on control sides compared to $19.8 \%$ on treatment sides receiving steroid releasing sinus implants $(p<0.0001)$, representing a $46 \%$ relative reduction. A study by Matheny et al. ${ }^{(12)}$ had similar results, where 20 patients receiving steroid eluting sinus implants following ESS in the fourth POW were evaluated for ethmoid sinus inflammation using visual analog scale. Mean ethmoid sinus inflammation was reduced from 25.6 at baseline to 22.6 at week 2 and 18.9 at week 4 . The reduction in inflammation at week 4 was statistically significant $(p=0.03)$. There was also a decline in crusting, however it was statistically insignificant. A study by Forwith et al. ${ }^{(11)}$ also yielded similar results, where 50 patients following ESS received steroid eluting sinus implant and were evaluated for up to 60 days. The mean inflammation scores were minimal at all time points, polypoid tissue formation at day 30 was only $10 \%$. In contrast, Taulu et al. ${ }^{(15)}$ did not obtain significant results favoring drug eluting sinus stents over the steroid nasal spray in cases with chronic rhinosinusitis.

\section{Limitations}

The study had few limitations. We didn't document the pre-operative severity of the disease and compare it with post-operative status. Differences in severity of the disease on each side might influence the outcomes. In extensive cases post-operative oral steroid were prescribed which may have some bias on post-operative outcomes. Endoscopic evaluation during follow up period was also early and the objective findings could be modified with time as the disease takes its natural course. Use of a steroid soaked nasal pack allowed contact duration with nasal mucosa of only 48 hours and this short duration of contact might not have yielded the optimal results.

This study can be reproduced for a longer duration with a larger sample size to yield more valid results. However, there are several constraints such as poor socioeconomic conditions, lack of health education, transportation difficulties etc. 


\section{Conclusions}

Triamcinolone soaked PVA pack following bilateral endoscopic sinus surgery provides good outcomes with improvement in healing and significant reduction in oedema and polypoidal mucosal change in the sinus cavities.

\section{Authorship contribution}

BRG: Principal investigator/ First author; BP: Chief Surgeon/ Coauthor; NT: Co-author.

\section{Conflict of interest}

All the authors state that there is no conflict of interest.

\section{Acknowledgements}

None

\section{References}

1. Côté DW, Wright ED. Triamcinolone - impregnated nasal dressing following ESS: a randomized, double-blind, placebo-controlled study. Laryngoscope 2010;120(6):1269-73.

2. Reychler G, Domachowski C, Latiers AC, Jamar F, Rombaux P. Clinical efficacy of intranasal drug delivery by nebulization in chronic rhinosinusitis: a systematic review. Rhinology. 2019 Apr;57(2):82-93.

3. Lund VJ, Kennedy DW. Staging for rhinosinusitis. Otolaryngol Head Neck Surg 1997:117: 35-40

4. Wright ED, Agrawal S. Impact of perioperative systemic steroids on surgical outcomes in patients with chronic rhinosinusitis with polyposis : evaluation with the novel perioperative sinus endoscopy (POSE) scoring system. Laryngoscope 2007;117:1-28.

5. Bettega S, Soccol AT, Koerner HN Mocellin M. Epidemiological Analisys in Patients with Nasal Polyps. Int Arch Otorhinolaryngol. 2007:11(3):243-24.

6. Settipane GA. Allergy and Asthma Proceedings; 1996: OceanSide Publications, Inc.

7. Meymane Jahromi A, Shahabi Pour A. The Epidemiological and Clinical Aspects of
Nasal Polyps that Require Surgery. Iran J Otorhinolaryngol. 2012;24(67):75-8.

8. Rudmik L, Mace J, Mechor B. Effect of a dexamethasone Sinu-Foam TM middle meatal spacer on endoscopic sinus surgery outcomes in patients with chronic rhinosinusitis without nasal polyposis: a randomized, double-blind, placebo-controlled trial. Int Forum Allergy Rhinol, 2012; 2:248-251.

9. Murr AH, Smith TL, Hwang PH, et al. Safety and efficacy of a novel bioabsorbable, steroid eluting sinus stent. Int Forum Allergy Rhinol, 2011; 1:23-32.

10. Han JK, Marple BF, Smith TL, et al. Effect of steroid releasing sinus implants on postoperative medical and surgical interventions: an efficacy meta-analysis. Int Forum Allergy Rhinol, 2012; 2:271-279.

11. Forwith KD, Chandra RK, Yun PT, Miller SK, Jampel HD. ADVANCE: A multisite trial of bioabsorbable steroid eluting sinus implants. Laryngoscope 2011;121(11): 2473-80.

12. Matheny KE, Carter KB Jr, Tseng EY, Fong KJ. Safety, feasibility, and efficacy of placement of steroid-eluting bioabsorbable sinus implants in the office setting : a prospective case series. Int Forum Allergy Rhinol. 2014;4:808-815.
13. Vento SI, Blomgren $\mathrm{K}$, Hytonen M, Simola M Malmberg $H$. Prevention of relapses of nasal polyposis with intranasal triamcinolone acetonide after polyp surgery : a prospective double blind, placebo-controlled, randomized study with a 9-month follow- up Clinical Otolaryngology 2012;37(2):117-23.

14. Taulu R, Bizaki AJ, Numminen J, Rautiainen M. A prospective, randomized clinical study comparing drug eluting stent therapy and intranasal corticoid steroid therapy in the treatment of patients with chronic rhinosinusitis. Rhinology. 2017;55(3):218-26.

Dr. Bigyan Raj Gyawali

Department of ENT-HNS

Institute Of Medicine

Tribhuvan University Teaching

Hospital

Kathmandu

Nepal

Tel: +97-798-0310 5062

E-mail: bigyan.gyawali@gmail.com 